\title{
ОСОБЕННОСТИ ОРГАНИЗАЦИИ СТРАТЕГИЧЕСКОГО ПЛАНИРОВАНИЯ ЭНЕРГЕТИЧЕСКИХ КОМПАНИЙ РОССИИ
}

\author{
Л. В. Калимуллин
}

Казанский (Приволжский) федеральный университет

Поступила в редакцию 25 декабря 2019 г.

\begin{abstract}
Аннотация: представлена оченка текущего положения и тенденций в сфере стратегирования на основе анализа стратегий развития энергетических компаний и програмл долгосрочного развития государственных корпораций и компаний с государственным участием, проведен структурно-содержательный анализ документов стратегического планирования, в том числе нормативных правовых актов и методических документов в сфере стратегического планирования. Систематизированы основнье требования к содержанию стратегий. Проведенный анализ позволяет сделать вывод о разном уровне качества стратегического планирования среди электроэнергетических компаний и основных факторах, их характеризующих. Поскольку в энергетике происходят существенные изменения, низкий уровень стратегирования негативным образом сказывается на дальнейших перспективах не только компаний и отрасли, но и общества в целом. Используя положительный опьт компаний с государственньлм участием по качеству разработанных стратегических документов и системы стратегического планирования в целом, государство в лице отраслевого министерства может стать ключевым драйвером повышения эффективности стратегического управления и, как следствие, конкурентоспособности отрасли.
\end{abstract}

Ключевые слова: стратегическое планирование, стратегия развития, долгосрочная программа развития, энергетика, энергетические компании, повышение стоимости.

\begin{abstract}
: the review of current condition and trends of strategizing is presented in this publication which is based on analysis of companies' growth strategies and long term development programs of government-owned corporations and partially government-owned companies'. Structural informative analysis of strategic planning documents had been conducted as well as regulatory acts and strategic planning methodical documents overview. Key requirements for strategy content list had been systematized. Conducted analysis provides the opportunity to make a conclusion on diverse quality levels of strategic planning among electric power companies and its main revealing drivers. Considering significant changes in energy sector poor standards of strategizing adversely effects on not only companies and economic sector but mainstream society future trends as a whole. National government through the line ministry may become a key driver to strategic management efficiency improvement and competitive strength of the economic sector as a result taking in consideration a successful practices and quality of strategic documents and strategic planning system in general.
\end{abstract}

Key words: strategic planning, development strategy, long-term development program, energy, energy companies, value increase.

В условиях невысоких темпов экономического роста как на федеральном, так и на отраслевом уровне обостряется вопрос эффективности управления энергокомпаниями. Теоретической основой для обеспечения сбалансированности развития такой сложно-функциональной системы, как хозяйствующий субъект, осуществляющий производство, передачу и распределение электрической энергии, и повышения эффективности его управленческой деятельности является стоимостной подход к управлению, признанный наиболее оптимальной системой стратегического управления, и теория конкурентных

(C) Калимуллин Л. В., 2020 стратегий Портера [1]. Вместе с программно-целевым подходом планирования деятельности хозяйствующих субъектов они позволяют сконцентрировать имеющиеся ресурсы на приоритетной цели в условиях нестабильной внешней среды, снизить институциональные и операционные издержки на систему управления. Однако указанный механизм требует комплексного подхода к формированию стратегического видения будущего, построению четких и продуманных траекторий движения компании. Качественный процесс стратегического планирования (стратегирования) ведет к повышению ее эффективности и конкурентоспособности, а также становлению целостной системы управления компанией. 


\section{Постановка проблемы и обзор ранее выполненных исследований}

Стратегическое управление энергетической компанией - это деятельность, направленная на достижение запланированных долгосрочных целей, среди которых рост надежности и безопасности, рост конкурентоспособности, достижение определенного положения компании на рынке, увеличение рыночной стоимости, ее прибыли [2]. Концептуальная модель стратегического управления энергокомпанией представляет собой динамичную совокупность взаимосвязанных управленческих процессов, следующих один за другим с учетом существующей устойчивой обратной связи и, соответственно, с обратным влиянием каждого процесса на остальные и на всю их совокупность [3].

Вопросам стратегического управления крупными промышленными холдингами в научной экономической литературе уделено значительное внимание. Первые работы в области стратпланирования в России (в рамках периода российской государственности) появились в начале 1990-х гг., через несколько лет после распада СССР. Поэтому теоретические и методологические основы стратегирования, в том числе на корпоративном уровне, начали закладываться в российской науке начиная с данных событий [4]. Исследования, проведенные на данном этапе, затрагивают широкий перечень направлений теоретического и прикладного характера, связанных с современным состоянием стратегического планирования сложных корпоративных хозяйствующих субъектов, к числу которых относятся электроэнергетические компании.

Вместе с тем в настоящее время актуальна задача формирования единой и логически взаимосвязанной системы стратегирования и программирования на уровне компаний электроэнергетической отрасли.

\section{Полученные результаты и их обсуждение}

Исследование основывается на обзоре законодательства и методических рекомендаций, подготовленных федеральными органами государственной власти, в сфере разработки стратегий и долгосрочных программ развития, размещенных в базах данных нормативных правовых актов, включая стратегические документы электроэнергетических компаний России.

Основными методами анализа явились контент-анализ, индуктивный и дедуктивный метод.

Ключевыми оцениваемыми характеристиками для стратегирования электроэнергетических ком- паний стали наличие документов стратегического планирования, полнота содержания, период планирования, специфика и особенности участников стратегического управления, перечень документов стратегического планирования, регламентный порядок осуществления стратегического планирования, целеполагание, характеристика отдельных элементов.

Выделяется несколько этапов в развитии стратпланирования в корпоративном секторе в России. На первом этапе, с 1993 по 2003 г., действовали планы и программы развития хозяйствующих субъектов, которые определяли задачи и ключевые мероприятия развития энергокомпаний, а также общий порядок их разработки. Этот период связан с принятием и реализацией многочисленных федеральных программ развития страны.

Второй этап, с 2003 по 2008 г., условно берет начало с момента утверждения советом директоров ОАО РАО «ЕЭС России» 29 мая 2003 г. Концепция стратегии ОАО РАО «ЕЭС России» «5+5». Стратегия была нацелена на реформирование РАО «ЕЭС России», выделение к 2006 г. всех узловых субъектов отрасли и последующее завершение необходимых корпоративных процессов.

Начали появляться первые обобщения научных основ разработки документов долгосрочного развития энергокомпаний в рыночных условиях [5-10]. Процесс стратегического управления стал предметом регулярного обсуждения на форумах и конференциях [11].

Следующий период, с 2009 по 2013 г., характеризовался завершением в 2008 г. деятельности ОАО РАО «ЕЭС России», соответствующим изменением состава участников электроэнергетической отрасли и активной разработкой стратегий энергокомпаний, которые пытались в рамках процесса стратегического планирования определить свою идентичность и видение, какими должны быть компании в стратегической перспективе. Стратегирование и формирование долгосрочных направлений развития стало общепринятой важнейшей задачей.

Наиболее значимые, принципиальные изменения произошли в 2014 г., когда был принят Федеральный закон № 172-Ф3 «О стратегическом планировании в Российской Федерации» (далее - Федеральный закон № 172-Ф3). Несмотря на то что данный закон определяет регуляторные нормы и обязательные элементы применительно для процесса стратегического планирования страны в целом и уровня субъектов Федерации в частности, после его принятия развернулась активная работа по кор- 
ректировке и актуализации документов стратегического планирования компаний с учетом новых требований как содержательного, так и институционального характера. Этому также способствовала разработка Министерством экономического развития Российской Федерации совместно с Федеральным агентством по управлению государственным имуществом Методических рекомендаций по разработке долгосрочных программ развития стратегических открытых акционерных обществ и федеральных государственных унитарных предприятий, а также открытых акционерных обществ, доля Российской Федерации в уставных капиталах которых в совокупности превышает пятьдесят процентов, позднее одобренных поручением Правительства Российской Федерации от 15 апреля 2014 г. № ИШ-П13-2583. Компаниям с государственным участием, в том числе в электроэнергетической сфере, надлежало разработать новые «документы, являющиеся производными от стратегий госкомпании и представляющие собой программный документ, содержащий перечни средств и конкретных мероприятий, обеспечивающих достижение стратегических целей развития организации, определенных Стратегией ее развития, к поставленным срокам с указанием объема и источников их финансирования, включающий значения показателей текущих и ожидаемых результатов деятельности организации, ее дочерних и зависимых организаций, филиалов на период от 5 лет». Данные требования не затронули частные компании, но на деле, учитывая высокую долю участия государства в отрасли, в большинстве крупных электроэнергетических компаний (ПАО «Интер РАО», ПАО «Россети», ПАО «ФСК», ПАО «РусГидро», АО «Системный оператор ЕЭС») в 2014 г. стартовал процесс разработки и утверждения долгосрочных программ развития.

Разработка долгосрочных программ развития стала новым инструментом в системе стратегического планирования. Программы стали частью процесса внедрения программно-целевых методов в деятельности электроэнергетических компаний, с помощью которых федеральные органы власти реализуют и контролируют поручения президента страны, а также обеспечивают реализацию промышленной политики в целом. В настоящее время именно долгосрочные программы развития представляют собой основу для контроля за инвестиционными, производственными и инновационными программами предприятий с государственным участием и достижения ими ключевых показателей эффективности. Государство в данном случае выступает одновременно в роли как регулятора их деятельности, так и основного акционера (собственника).

Важно отметить, что разработка долгосрочных программ развития не отменяет необходимости формирований стратегий компании, поскольку в таком слабопрогнозируемом секторе, как отрасль энергетики (и с точки зрения технологических аспектов, и с точки зрения экономических аспектов), существует принципиальная невозможность определения перспектив на основе методов экстраполяции [12]. Поскольку неопределенность внешней среды имеет высокую степень, возрастает значимость осуществления энергокомпаниями стратегического анализа и определения направления повышения собственной конкурентоспособности. Отсюда представляется невозможным объединение этих двух документов (стратегии и долгосрочной программы развития) в один консолидированный стратегический документ.

По итогам утверждения закона о стратегическом планировании и формирования рекомендаций по разработке долгосрочных программ развития в компаниях активно развернулся процесс актуализации и разработки стратегий с учетом новых требований нормативного правового регулирования, а также их плановой корректировки. Вместе с тем, несмотря на всплеск интереса к стратегическому планированию, обусловленного утверждением Федерального закона № 172-ФЗ и проходящими в настоящий момент процессами по формированию стратегии страны и актуализации федеральной энергетической стратегии, к настоящему времени не все крупные электроэнергетические компании имеют такой документ, как стратегия развития компании. К данным компаниям в определенной степени относятся ПАО «Россети» и ПАО «ФСК», руководствующиеся в своей работе утвержденной в 2013 г. Стратегией развития электросетевого комплекса Российской Федерации, но не обладающие собственными корпоративными стратегиями, или электроэнергетические компании, входящие в группу «Газпром», стратегия для которых определяется Стратегией ПАО «Газпром» в электроэнергетике.

Необходимо отметить, что стратегии электроэнергетических компаний утверждаются советами директоров соответствующих обществ, однако их утверждению предшествует длительный процесс согласования с экспертным сообществом и органами власти (не только в случае участия государ- 
ства в качестве собственника), что непосредственным образом сказывается на качестве документов стратегического планирования энергокомпаний. Процесс стратегирования заметно развивается, и значительную роль в этом играет участие стейкхолдеров, общественных институтов и портфельных инвесторов, а также проведение научной экспертизы.

На настоящий момент нет единой формализованной позиции в части обязательных требований по содержанию стратегий развития электроэнергетических компаний. Так, в соответствии с Федеральным законом № 172-ФЗ стратегия должна включать множество параметров, начиная с оценки достигнутых целей развития и заканчивая механизмами ее реализации. Однако данные требования закон устанавливает для государственных (федеральных и региональных) и отраслевых стратегий. Доведенные до компаний с государственным участием требования Роси- мущества от 29 апреля 2014 г. № ОД-11/18576 в качестве обязательных элементов стратегии предполагают цели развития организации, информацию о положении в отрасли, целевую финансовую бизнес-модель и стратегические инициативы. Наиболее обширные требования по содержанию зафиксированы в письме Росимущества от 27 марта 2012 г. № ГН-15/9084. Они предполагают наличие миссии, стратегических целей, целевой бизнес-модели, показателей, а также приоритетных направлений и задач. Кроме того, для государственных компаний в стратегических документах, в соответствии с директивой Правительства Российской Федерации от 28 июня 2016 г. № 4531п-П13, обязателен раздел, обеспечивающий приоритетный характер финансирования задач социально-экономического развития Дальнего Востока. Основные требования к содержанию стратегий энергокомпаний приведены в табл. 1.

Т а бли ц а 1

Основные требования к содержанию стратегий

\begin{tabular}{|c|c|c|c|c|c|}
\hline Разделы & \begin{tabular}{|c|} 
Федеральный закон \\
«О стратегическом \\
планировании в РФ» \\
от 28.06 .2014 \\
№ $172-\Phi 3^{1}$ \\
\end{tabular} & \begin{tabular}{|} 
Приказ МЭР \\
России От \\
18.11 .2011 \\
№ 683
\end{tabular} & $\begin{array}{c}\text { Письмо } \\
\text { Росимущества } \\
\text { от } 29.04 .2014 \\
\text { № ОД- } 11 / 18576\end{array}$ & $\begin{array}{c}\text { Письмо } \\
\text { Росимущества } \\
\text { от } 27.03 .2012 \\
\text { № ГН-15/9084 }\end{array}$ & $\begin{array}{l}\text { Стратегии } \\
\text { компаний }\end{array}$ \\
\hline Период & От 6 лет & 3-5 лет & Не менее 5 лет & $\begin{array}{c}\text { На период 5-10 } \\
\text { лет или более }\end{array}$ & От 5 лет \\
\hline $\begin{array}{l}\text { Оценка текущей ситуации и } \\
\text { степени достижения целей }\end{array}$ & $\vee$ & $\vee$ & & $\vee$ & $\vee$ \\
\hline $\begin{array}{l}\text { Оценка позиции во внешнем } \\
\text { окружении }\end{array}$ & $\vee$ & $\vee$ & $\vee$ & $\vee$ & $\vee$ \\
\hline Видение компании & & $\vee$ & & & $\vee$ \\
\hline Миссия & & & & & V \\
\hline Цели & $\mathrm{V}$ & $\vee$ & $\vee$ & $\vee$ & $\mathrm{V}$ \\
\hline Ценности & & & & & $\mathrm{V}$ \\
\hline $\begin{array}{l}\text { Целевые показатели деятель- } \\
\text { ности }\end{array}$ & $\vee$ & $\vee$ & $\vee$ & $\vee$ & $\vee$ \\
\hline $\begin{array}{l}\text { Условия, факторы, ограничения } \\
\text { и риски достижения поставлен- } \\
\text { ных целей и показателей }\end{array}$ & $\vee$ & $\vee$ & & & $\vee$ \\
\hline $\begin{array}{l}\text { Приоритетные направления } \\
\text { развития }\end{array}$ & V & $\vee$ & & $\vee$ & $\vee$ \\
\hline Задачи развития & $\vee$ & & & $\vee$ & $\vee$ \\
\hline $\begin{array}{l}\text { Мероприятия (стратегические } \\
\text { инициативы) }\end{array}$ & $\vee$ & $\vee$ & $\vee$ & $\vee$ & $\vee$ \\
\hline $\begin{array}{l}\text { Укрупненный/детальный план } \\
\text { реализации стратегии }\end{array}$ & $\vee$ & $\vee$ & & & $\vee$ \\
\hline $\begin{array}{l}\text { Целевая финансово-экономиче- } \\
\text { ская модель }\end{array}$ & & $\vee$ & $\vee$ & $\vee$ & $\vee$ \\
\hline Механизмы & $\vee$ & $\vee$ & & $\vee$ & $\vee$ \\
\hline
\end{tabular}

${ }^{1}$ Устанавливает требования для государственных и отраслевых стратегий. 
В большинстве стратегий соответствующие разделы присутствуют, хотя подходы к их формированию и само содержание сильно отличаются друг от друга. В компаниях также сформировались свои взгляды и на методы планирования - широко используется проведение стратегических сессий и «форсайтов», являющихся прямыми аналогами западных образцов технологий стратегического управления.

Утвержденные документы компаний также характеризуются различным качеством исполнения.

Анализ корпоративных документов свидетельствует, что горизонт стратегического планирования энергокомпаний различен (рисунок). Наблюдаемая широкая вариативность сроков и периодов реализации связана с отсутствием единого горизонта стратегического планирования у государственных стратегий в целом, даже несмотря на то, что связь корпоративных стратегий и системы государственного стратпланирования практически не формализована [13]. Как правило, компании выдерживают минимальный порог продолжительности стратегии в 5 лет.

Наиболее «популярны» периоды до 2020 г. и 2030 г., при этом основания для выбора различаются от компании к компании. Среди причин можно выделить следующие: срок действующей энергетической стратегии России, срок стратегии развития субъекта Федерации, срок реализации основной части инвестиционных проектов. Лидерами по сроку продолжительности реализации стратегии являются АО «Татэнерго» (19 лет), ПАО «Россети» (18 лет), ГК «Росатом» (17 лет). Компания с наименьшим горизонтом планирования - Энел Россия (3 года). Большинством компаний предполагается периодическая актуализация стратегий, к примеру, как в ПАО «РусГидро», каждые 5 лет.

Главная (наиболее часто встречающаяся) стратегическая цель развития энергокомпаний России состоит в обеспечении надежного и безопасного функционирования энергообъектов (табл. 2). Еще одной важной целью является повышение инвестиционной и операционной эффективности, что обусловлено в немалой степени тем, что компании функционируют в конкурентном сегменте экономики, а также значительным уровнем инвестиций ввиду высокого уровня физического износа оборудования и объектов [14].

Можно отдельно выделить, что в стратегиях российских компаний все большую значимость приобретает цель роста стоимости и повышения привлекательности для акционеров, что подтверждается включением в число ключевых показателей стратегических документов показателя доходности для акционеров (TSR). В этих условиях ключевой стратегической инициативой является внедрение стоимостного подхода в управлении, обеспечивающего ориентацию управленческих регламентов, процессов и решений на увеличение стоимости компании при обязательном обеспечении надежного и безопасного функционирования своих объектов.

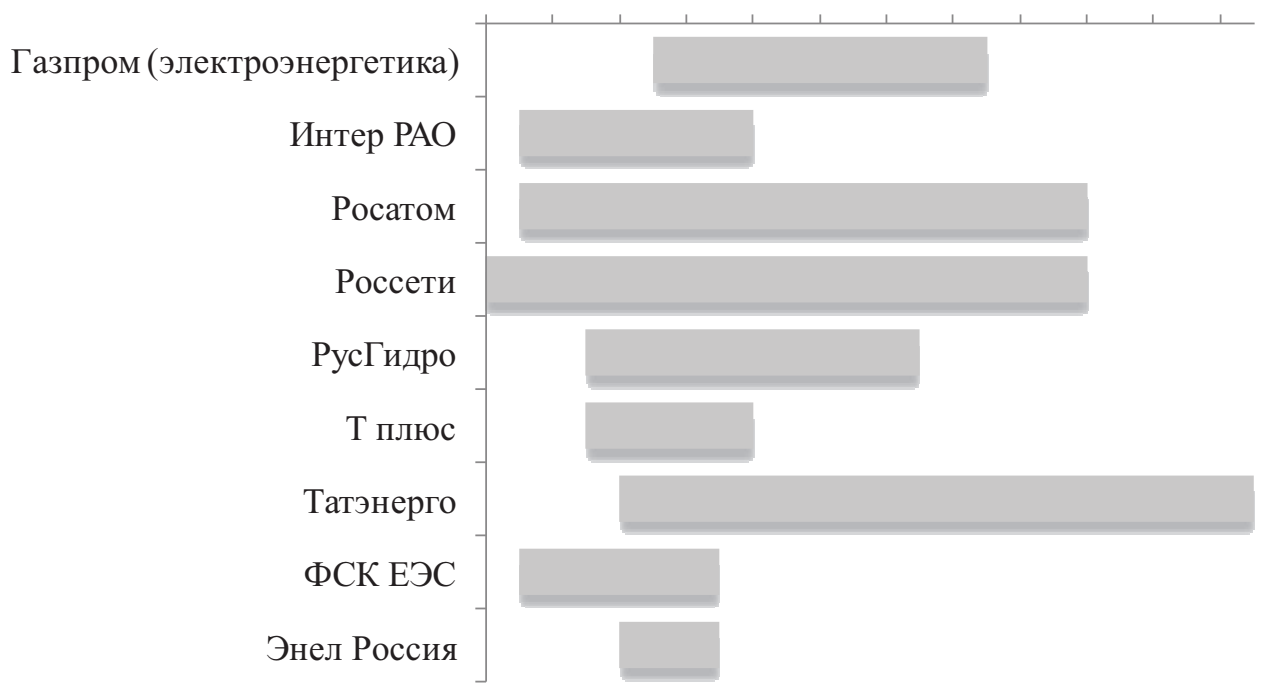

Рисунок. Длительность стратегий развития электроэнергетических компаний (составлено согласно информации, предоставленной компаниями) 
Приоритетные направления развития ключевых энергетических компаний России

\begin{tabular}{|c|c|}
\hline Компания & Стратегические направления развития энергетических компаний \\
\hline $\begin{array}{l}\text { Газпром (элек- } \\
\text { троэнергетика) }\end{array}$ & $\begin{array}{l}\text { - Обеспечение надежного и бесперебойного производства электрической и тепловой энергии. } \\
\text { - Реализация инвестиционных программ генерирующих компаний. } \\
\text { - Повышение капитализации электроэнергетических активов ПАО «Газпром». } \\
\text { - Повышение операционной эффективности электроэнергетических активов ПАО «Газпром». } \\
\text { - Внедрение энергосберегающих технологий, разработка и применение методик, основанных } \\
\text { на принципах рационального использования энергоресурсов }\end{array}$ \\
\hline Интер РАО & $\begin{array}{l}\text { - Сохранение лидерских позиций в российской энергетике. } \\
\text { - Обеспечение лидерства среди российских энергокомпаний в области эффективности управ- } \\
\text { ления энергоактивами с курсом на внедрение инноваций и повышение энергетической эффек- } \\
\text { тивности. } \\
\text { - Рост акционерной стоимости. } \\
\text { - Расширение присутствия на целевых зарубежных рынках, а также продвижение на зарубеж- } \\
\text { ные рынки российской практики и решений в сфере энергетики. } \\
\text { - Содействие энергетической безопасности и обеспечению стратегических интересов Россий- } \\
\text { ской Федерации }\end{array}$ \\
\hline Росатом & $\begin{array}{l}\text { - Повышение доли на международных рынках. } \\
\text { - Снижение себестоимости продукции и сроков протекания процессов для создания самого } \\
\text { конкурентного продукта. } \\
\text { - Создание новых продуктов для российского и международных рынков с учетом накоплен- } \\
\text { ных знаний и технологий «атомного проекта» в гражданских отраслях }\end{array}$ \\
\hline Россети ${ }^{2}$ & $\begin{array}{l}\text { - Обеспечение надежности энергоснабжения потребителей. } \\
\text { - Обеспечение качества их обслуживания. } \\
\text { - Развитие инфраструктуры для поддержания роста экономики России. } \\
\text { - Конкурентоспособные тарифы на электрическую энергию для развития промышленности. } \\
\text { - Развитие научного и инновационного потенциала электросетевого комплекса, в том числе в } \\
\text { целях стимулирования развития смежных отраслей. } \\
\text { - Привлекательный для инвесторов «возврат на капитал» }\end{array}$ \\
\hline РусГидро & $\begin{array}{l}\text { - Обеспечение надежного и безопасного функционирования объектов компании. } \\
\text { - Устойчивое развитие производства электроэнергии. } \\
\text { - Развитие энергетики Дальнего Востока. } \\
\text { - Рост ценности компании }\end{array}$ \\
\hline Татэнерго & $\begin{array}{l}\text { - Увеличение объемов производства электрической и тепловой энергии станциями компании. } \\
\text { - Обеспечение конкурентоспособности производимой на рынке продукции. } \\
\text { - Повышение качества управления компанией путем эффективного управления человечески- } \\
\text { ми ресурсами и принятия решений за счет внедрения информационно-коммуникационных } \\
\text { технологий. } \\
\text { - Снижение негативного воздействия на окружающую среду за счет повышения энергоэффек- } \\
\text { тивности технологического процесса }\end{array}$ \\
\hline Т плюс & $\begin{array}{l}\text { Обеспечение надежного и бесперебойного производства электрической и тепловой энергии. } \\
\text { Строительство новых и повышение эффективности действующих мощностей посредством } \\
\text { реализации приоритетной инвестиционной программы. } \\
\text { Внедрение энергосберегающих технологий, содействие повышению энергоэффективности } \\
\text { российской экономики. } \\
\text { Увеличение капитализации и инвестиционной привлекательности компании, повышение энер- } \\
\text { гоэффективности через развитие производства электроэнергии на базе возобновляемых источ- } \\
\text { ников энергии }\end{array}$ \\
\hline$\Phi \Phi^{3}$ & $\begin{array}{l}\text { - Обеспечение надежности и качества услуг. } \\
\text { - Сохранение финансовой устойчивости и независимости и рост стоимости. } \\
\text { - Развитие ЕНЭС с учетом технической и экономической оптимизации магистральных сетей. } \\
\text { - Удовлетворение спроса потребителей на услуги с учетом региональных особенностей, } \\
\text { структуры спроса и повышения эффективности загрузки мощностей. } \\
\text { - Консолидация под управлением компании всех объектов электросетевого хозяйства, входя- } \\
\text { щих в ЕНЭС и соответствующих критериям отнесения к ЕНЭС }\end{array}$ \\
\hline Энел Россия & $\begin{array}{l}\text { - Комплексная оптимизация затрат, включая дальнейший пересмотр программы капитальных } \\
\text { затрат и сдерживание роста операционных расходов ниже уровня инфляции. } \\
\text { - Обеспечение эффективности и надежности работы оборудования. } \\
\text { - Оптимизация структуры задолженности }\end{array}$ \\
\hline
\end{tabular}

Источник: сайты и годовые отчеты компаний.

${ }^{2}$ В соответствии с распоряжением Правительства РФ от 3 апреля 2013 г. № 511-р «Об утверждении Стратегии развития электросетевого комплекса Российской Федерации».

${ }^{3} \mathrm{~B}$ соответствии с Долгосрочной программой развития ПАО «ФСК». 
Важной особенностью крупных энергокомпаний с высокой долей участия государства является высокий приоритет в стратегических документах задач, поставленных государством, а также гибридная форма государственного и корпоративного стратегирования. Нельзя не отметить и формирование стратегической ориентации энергокомпаний на устойчивое развитие под влиянием государства и общества.

В целом уровень владения передовыми практиками стратегического планирования в электроэнергетических компаниях может оцениваться как неоднородный. Ряд энергокомпаний характеризуется высоким уровнем компетенций в сфере стратегического планирования, соответствующих лучшим мировым практикам и условиям высокой конкурентной среды, а также задачам технологического и инновационного развития. При этом у большой части компаний нет стратегий своего развития - ни формализованных, ни понятийных. Более того, в то время как мировая энергетика находится на пороге существенных изменений, основанных на совершенствовании имеющихся технологий, идей и моделей управления, которые будут определять профиль отрасли и существенным образом повлияют на будущее энергетики и энергетических компаний [15], и как никогда важно стратегическое видение и понимание своего места в «будущей» энергетике, у многих энергетических компаний отсутствуют планы по формированию стратегий своего развития в ближайшей перспективе. Отсутствие стратегирования негативным образом скажется на конкурентоспособности компаний и дальнейших перспективах не только отрасли, но и общества в целом.

Возможным решением данной проблемы может стать управляющая роль отраслевого министерства, которое либо самостоятельно, либо посредством подведомственных организаций должно активизировать работу среди всех энергетических компаний по формированию эффективных систем стратегического управления и разработки

\section{ЛИТЕРАТУРА}

1. Портер Е. Майкл Конкурентная стратегия : Методика анализа отраслей и конкурентов : пер. с англ. / Майкл Е. Портер. - М. : Альпина Бизнес Букс, 2005. $454 \mathrm{c}$.

2. Эльбакян A. М. Стратегическое управление энергетической компанией / А. М. Эльбакян // Вопросы экономики и права - 2015. - № 4 - С. 72-78.

3. Исмагилов Ш. И. Оценка эффективности деятельности промышленных холдингов в системе стратегиче- качественных стратегий, в том числе посредством использования лучших практик в отрасли, методологической и экспертной поддержки, проведения с участием топ-менеджмента компаний стратегических и форсайт-сессии и т. п.

Процесс формирования стратегических документов электроэнергетических компаний активизировался в 2014 г. в связи с принятием закона о стратегическом планировании и утверждением методологии по формированию долгосрочных программ развития госкомпаний. В противовес этому ситуация в макроэкономике, угрозы санкционного давления, отсутствие актуальной отраслевой стратегии существенно сдерживают активность компаний в осуществлении им стратегического планирования.

Проведенный обзор стратегий позволяет сделать вывод о недостаточном качестве стратегического планирования электроэнергетических компаний, что является причиной отсутствия вовлеченности стейкхолдеров, институциональных и портфельных инвесторов в процесс формирования стратегии, отсутствия четких требований по ее содержанию и недостаточного уровня квалификации разработчиков стратегических документов.

Результаты исследования показали, что государство является важным драйвером ориентации хозяйствующих субъектов на повышение эффективности стратегирования и выстраивания целостной системы стратегического управления. Компании с государственным участием характеризуются более высоким качеством разработанных стратегий своего развития и системы стратегического планирования в целом.

Именно поэтому решением проблемы отсутствия или низкого качества стратегий развития энергетических компаний может стать политика отраслевого министерства по формированию эффективных систем стратегического управления в энергокомпаниях, методологическая и экспертная поддержка в рамках разработки стратегий, а также проведение стратегических и форсайт-сессий.

ского управления : автореф. дис. ... канд. экон. наук / Ш. И. Исмагилов. - Казань : Казанский государственный финансово-экономический институт, 2007. - 237 с.

4. Климанов В. В. Направления регионального стратегирования и программирования в России / В. В. Климанов, К. В. Будаева, Н. А. Чернышева // Региональные исследования. - 2016. - № 4. - С. 17-30.

5. Баитов А. В. Обоснование количественная оценка стратегических целей развития региональных электросетевых компаний : автореф. дис. ... канд. экон. наук / 
А. В. Баитов. - М. : Государственный университет управления, 2006. - $150 \mathrm{c.}$

6. Еськов А. Н. Разработка и реализация стратегии развития энергетического предприятия в условиях реформирования отрасли : автореф. дис. ... канд. экон. наук / А. Н. Еськов. - СПб. : Санкт-Петербургский университет экономики и финансов, 2007. - 160 с.

7. Негомедзянова E. A. Разработка моделей и методов стратегического планирования инвестиционной деятельности генерирующей компании : автореф. дис. ... канд. экон. наук / Е. А. Негомедзянова. - М. : Московский энергетический институт, 2007. - 198 с.

8. Одина О. Ю. Обоснование стратегии развития промышленных предприятий (на примере региональной сетевой энергокомпании) : автореф. дис. ... канд. экон. наук / О. Ю. Одина. - Рязань : Рязанский государственный радиотехнический университет, 2006. $141 \mathrm{c}$.

9. Пузов Н. E. Внедрение в компании стратегии, ориентированной на создание ее стоимости / Н. Е. Пузов, Н. С. Яшин // Экономический анализ : теория и практика. - 2008. - № 12 - С. 36-39.

10. Тимофеев Д. И. Современная энергетическая компания : теория и практика стратегического управле-

Казанский (Приволжский) федеральный университет

Калимуллин Л. В., докторант

E-mail:l.v.kalimullin@mail.ru ния / Д. И. Тимофеев // Микроэкономика. - 2008. - № 1. С. $130-137$.

11. Проблемы развития российской энергетики : материалы науч. сессии Президиума Сибирского отделения РАН, 24 февр. 2005 г., Новосибирск / отв. ред. В. М. Задорожный, В. К. Жидкова, А. А. Валиуллина. Новосибирск : Издательство СО РАН, 2005. - 225 с.

12. Дьяконов А. Ф. Менеджмент и маркетинг в электроэнергетике / А. Ф. Дьяконов, В. В. Жуков, Б. К. Максимов, В. В. Молодюк. - М. : Издательский дом МЭИ, 2007. - 504 с.

13. Ваганов Д. А. Особенности организации стратегического планирования в крупных компаниях с государственным участием / Д. А. Ваганов. - М. : Экспертно-консультационный совет при Росимуществе, 2014. $39 \mathrm{c.}$

14. Тимофеев Д. И. Монополия и конкуренция : эволюция стратегий энергокомпаний / Д. И. Тимофеев // Микроэкономика. - 2008. - № 6 - С. 43-48.

15. Калимуллин Л. В. Влияние технологических исследований и разработок на повышение стоимости энергетических компаний / Л. В. Калимуллин // Проблемы теории и практики управления. - 2019. - № 1. С. $92-100$.

Kazan (Volga region) Federal University

Kalimullin L. V., Doctoral Student

E-mail:l.v.kalimullin@mail.ru 